\title{
UN EDITORIAL FUERA DE LUGAR
}

\section{Victor Jairo Chinchilla G.*}

En el juego de fútbol, como en la mayoría de los juegos se da una falta que se llama "fuera de lugar". Toda jugada que se hace en esta situación es ilegítima bien sea porque está buscando ventajas o porque está aplicando una forma de jugar que no corresponde a las normas establecidas entre los participantes.

Tal imagen sirve para caracterizar el editorial del número anterior de LUDJCA PEDAGOGICA (número 2, página 2) que tiene como titulo "Mucho ruido y pocas nueces" en el cual se realiza una crítica a lo que se considera como "anquilosamiento de la Educación Física".

Afirmaciones como las planteadas en el citado editorial se repiten en la cotidianidad de las clases y otros espacios de la vida académica del Departamento de Educación Física y de la propia Universidad Pedagógica con la pretensión de expresar opiniones de inconformismo crítico, pero que de tanta repetición sin enriquecimiento de contenidos que solo se logra con trabajo investigativo, se convierten en esquemas que empantanan el avance de la Educación Física y son, no pocas veces, desalentadores para amplios sectores de profesores en formación y aún en ejercicio de su profesión, y ello, principalmente porque provienen de la Universidad que se considera el Alma Mater de la Educación Física en Colombia.

De una manera breve y por considerar que LUDICA PEDAGÓGICA expresa el pensamiento de la comunidad académica de la Educación Física, se plantean algunos elementos de controversia con el citado editorial que aquí se citarán como los subtítulos.

\section{"EL PROBLEMA DE LA EDUCACIÓN FISICA RADICA EN SU NATURALEZA DE PRACTICA SOCIAL PROCEDIMENTAL Y POR ELLO INSTRUMENTAL"}

Nos han aterrorizado con el adjetivo de que la Educación Física es una práctica y ya muchos, influidos por estas disquisiciones se arman de cuanto argumento etéreo encuentran para justificarse y buscar "alternativas" que les permitan "superar" ese inferior nivel" de lo práctico. En general estos esfuerzos quedan en un discurrir de verbalización sin lograr incidir en aquella "aterradora práctica instrumental". A manera de ejemplo, ¿no caben acá muchos proyectos de grado orientados con los "conceptos alternativos", con grandes disquisiciones, pero que en su realidad concreta corresponden a lo común y corriente? ¿No hay acá un avance discursivo no correspondiente con la práctica y por tanto estéril para transformarla?

La Educación Física es una práctica pero no en el sentido en que se le describe por el autor del editorial para quien en ella está el problema.

La Educación Física es una práctica construida socialmente en la cual la instrumentación y los procedimientos corresponden a un tipo de acción determinada por el interés social.

\footnotetext{
* Profesor Universidad Pedagógica Nacional 
No hay por tanto en ello problema que no sea la disposición adecuada para el logro de su encargo. Como práctica social es permanente, universal y se va construyendo conforme a aquellos fines que la sociedad asigna. El concepto de práctica conlleva un proceso de elaboración, que se da culturalmente. No hay pues práctica a secas y si lo que se quiere es criticar el instrumentalismo éste no estaría dado por el carácter práctico sino por le reducción muy lógicamente definida a un tipo de realizaciones que se han decantado socialmente y que hoy resultan eficientes para algo o alguien.

Más claramente, lo que está instrumentalizada es la sociedad y por tanto hay tendencias que instrumentalizan la Educación Física, al igual que la ciencia o el arte lo cual no significa que esa sea su naturaleza. Con más propiedad se podría afirmar que hay enfoques instrumentalistas de la Educación Física, pero no que toda ella es instrumental y por supuesto el verbalismo o el teoricismo no saca a la Educación Física del instrumentalismo sino que se constituye en otra de sus formas.

Las prácticas han tenido un largo proceso de experimentación y construcción social hasta decantar en gestos, movimientos y técnicas, de eficacia real para la vida del hombre, esto es, hechos que se realizan con claridad en sus finalidades.

Hace ya mucho tiempo en la historia de la humanidad se dio el paso del puro quehacer práctico al uso de los movimientos con una determinada finalidad y a la posterior reflexión, recreación e investigación sobre ellos, surgiendo la Educación Física como disciplina.

En torno a esta disciplina se han conformando distintos sistemas gimnásticos, de juego, de formas de organización y disposición del tiempo y el espacio, que corresponden a prácticas detrás de las cuales existen conceptos que las fundamentan tanto en sus componentes de totalidad como en sus aspectos parciales, los primeros orientados a principios y finalidades y los segundos a explicaciones detalladas de la acción, para su logro mismo y para el perfeccionamiento de la enseñanza.

Este proceso, largo y complejo, de paso del quehacer cotidiano a lo educativo, artístico o deportivo ha constituido un conocimiento disciplinar muy amplio de la Educación física que hoy tienen distintos enfoques de comprensión y explicación y que se constituyen en el objeto central de preocupaciones no solo de especialistas de la Educación Física sino de las más diversas disciplinas.

Es este un proceso particular y especial, que tiene su propia naturaleza, por lo que es vano el esfuerzo desesperado por pretende imponer a la Educación Física la lógica, los procedimientos y aún los mismos objetos de otras disciplinas. En este sentido, existe ya un amplio trabajo de pertinencia propia y de carácter interdisciplinario que desde hace años trabaja sobre el tema en la Educación Física colombiana y que, entre otras fue el motivo de la presencia del profesor Parlebas en el XIII Congreso Panamericano de Educación Física.

\section{“EL AGOTAMIENTO ESTRIBA EN EL EMPECINAMIENTO POR MANTENER COMO FUNDAMENTO EL MOVIMIENTO"}

Es este un planteamiento que desconoce el desarrollo histórico del movimiento desde el punto de vista de la Educación Física. Los conceptos y las prácticas que hoy fundamentan el movimiento en la Educación Física han tenido una evolución muy amplia y diversa, relacionada con el proceso social y cultural, y de los distintos enfoques pedagógicos y 
didácticos, así como de la participación de otras disciplinas. En cien años la ciencia se ha desarrollado: Las Ciencias Naturales y Sociales han hecho grandes aportes en el plano la actividad y la cultura física, las corrientes gimnásticas han logrado una enorme producción que se expresa en el trabajo de múltiples líneas y tendencias, el desarrollo del deporte ha enriquecido las prácticas, formas y las técnicas educativas y políticas; en el plano económico la producción se ha transformado y con ello las prácticas de trabajo, recreación y modos de vida. Este proceso de producción cultural ha enriquecido y transformado el movimiento corporal que asume diferentes formas de manifestación en la educación Física correspondientes a un momento histórico distinto al de Demeny, Didacus o Le Boulch (citados por el editorial). Es recomendable una mirada a la Historia de la Educación Física para apreciar la producción que en este campo se ha realizado, y en particular ver los aportes prácticos y teóricos que enriquecieron, superaron o negaron los enfoques de los autores citados. Además hay un gran desconocimiento sobre la concepción de Parlebás quien no desconoce el movimiento sino los enfoques limitados al mecanicismo y la parcialidad, que lo llevan a proponer la conducta motriz y la acción motriz.

Es igualmente estéril la interminable discusión que toma como base las oposiciones Cuerpo-Movimiento-Juego. Sería más importante un reubicación de estas discusiones hacia los planos de la investigación y la experimentación en torno a una forma diferente de ver, delimitar y afrontar los problemas de la Educación Física.

\section{“ACAMPAR A LA SOMBRA DEL DEPORTIVISMO”}

Este planteamiento desconoce la relación que como fenómeno social, y por tanto hecho de la cultura, tiene el deporte con la Educación Física. Esta, como disciplina, interpreta sus características y lo usa como medio o actividad educativa, como puede hacerlo con otra actividad por ejemplo la danza o el excursionismo. Y como práctica social, puede orientar su acción y usarlo como hecho cotidiano en medio de los múltiples intereses que pueda tener la sociedad sobre él; situación que sirve de ejemplo de los problemas de investigación y experimentación que la Educación Física debe asumir.

Se destacan aportes de profesores como Leonel Morales y Carlos Bolívar. Fue un Foro de trascendencia histórica en torno al desarrollo científico y social de la Educación Física.

En segundo lugar, esta preocupación que hoy es el interés predominante en la Educación Física colombiana ha permitido avanzar en el problema central de la Educación Física; su papel en la sociedad colombiana y las condiciones con que cuenta para cumplir ese papel.

La actitud de algunos sectores de la Educación Física frente al deporte es en varios casos espontánea y en otros parcializada al tomar la Educación Fisica como una etapa de preparación para el deporte o considerarla como actividad aislada. En ambos casos hay una forma particular de relación. Esto es, la forma de relación de la Educación Física con el deporte es múltiple y puede darse en distintos niveles y planos de formación, de uso como medio, de objeto de critica pedagógica y social, de referencia de problemas investigativos de carácter técnico o político.

Por ello, la visión que califica a la Educación Física "acampando a la sombra del deportivismo es tan unilateral y errada como la solución” de separación radical. 


\section{“EL PANORAMA DE LA EDUCACIÓN FÍSICA RESULTA POCO ALENTADOR”}

Es una opció que desconozco y especial, que tiene su propia naturaleza, por lo que es vano el esfuerzo desesperado por pretender imponer a la Educación Física la lógica, los procedimientos y aún los mismos objetos de otras disciplinas. En este sentido, existe ya un amplio trabajo de pertinencia propia y de carácter interdisciplinario que desde hace años trabaja sobre el tema en la Educación Física colombiana y que, entre otras fue el motivo de la presencia del profesor Parlebás en el XIII Congreso Panamericano de Educación Física.

\section{"CENTRARSE EN LA ANTROPOLOGÍA Y EN LA PEDAGOGÍA"}

El punto de llegada sobre la importancia de una construcción disciplinar para la Educación Física no puede ser su envió a "acampar a la sombra" de otras disciplinas. La propia Educación Física tiene los componentes que fundamentan su propia pertinencia y el campo en el cual se construye como disciplina. Pero no es este solo un problema de disquisiciones y verbalizaciones. Es ante todo un problema que se centra en la necesidad dc asumir su naturaleza de práctica social, cuyo eje dinamizador es el papel que cumple en la construcción de un nuevo país y la disposición de las condiciones prácticas y teóricas para lograrlo.

\section{BIBLIOGRAFÍAS}

BARREAU Jaques, MORNE. Epistemología y Antropología del Deporte, 1988, Barcelona.

LANGLADE Alberto, LANGLADE Nelly: Teoría General de la Gimnasia 1978 Stadium, Buenos Aires

MEINEL KURT. Didáctica del Movimiento. 1978. La Habana.

PARLEBAS, Pierre: Educación Física Moderna o Ciencia de la acción Motriz. 1991, ACPEF, Bogotá.

XIII CONGRESO PANAMERICANO DE EDUCACIÓN FÍSICA: Memorias. 1991 ACPEF, Bogotá. 